\title{
Left bundle branch block in serious hyperkalaemia: rate-dependency?
}

\author{
R. Joustra' ${ }^{1,2}$ M. Boulaksil ${ }^{1,2}$ - H. W. Meijburg1 • M. C. Daniëls ${ }^{1}$
}

Published online: 25 July 2016

(C) The Author(s) 2016. This article is available at SpringerLink with Open Access

\section{Dear Editor,}

Fransen et al. [1] published a Heart Beat in this journal showing a case with rate-dependent left bundle branch block (LBBB) in a patient with serious hyperkalaemia. Critical appraisal of the ECGs, however, suggests that the hyperkalaemia by itself may be the explanatory mechanism of the LBBB rather than the increased heart rate. As shown in Fig. 1, the QRS complex immediately following a prolonged RR interval ( $10^{\text {th }} \mathrm{QRS}$ complex) is still widened, ruling out rate dependency as the underlying cause of left

M. Boulaksil

m.boulaksil@gmail.com

1 Department of Cardiology, Jeroen Bosch Hospital, 's-Hertogenbosch, The Netherlands

2 Department of Cardiology, Radboud University Medical Center, Nijmegen, The Netherlands bundle branch aberrancy in this case. Possibly, there was a time interval between the two ECGs explaining the occurrence of LBBB here. If the second ECG was performed after initiation of therapy, a decrease in the potassium level rather than the heart rate would be more explanatory.

Open Access This article is distributed under the terms of the Creative Commons Attribution 4.0 International License (http:// creativecommons.org/licenses/by/4.0/), which permits unrestricted use, distribution, and reproduction in any medium, provided you give appropriate credit to the original author(s) and the source, provide a link to the Creative Commons license, and indicate if changes were made.

\section{References}

1. Fransen NE, de Vos L, van Kesteren HA. Rate-dependent left bundle branch block caused by hyperkalaemia. Neth Heart J. 2016;24(3):217-8. doi:10.1007/s12471-015-0795-1. 


\section{Advertisement placed here.}

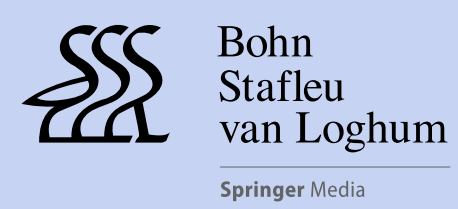

Houten 2016 